\title{
SUBSÍDIOS PARA A PRÉ-HISTÓRIA DO PRIMEIRO ESTABELECIMENTO DE ENSINO DA CONTABILIDADE EM PORTUGAL (1759)
}

Miguel Gonçalves:

RESUMO: O objectivo do artigo consiste em descrever alguns dos problemas prévios à fundação, pelo Marquês de Pombal, em 1759, da primitiva Aula de Comércio de Lisboa, primeira instituição de ensino em Portugal a ministrar instrução contabilística. Adicionalmente, o estudo pretende enquadrar histórica, política e socialmente a origem do ensino comercial no nosso país, empreendendo-se para o efeito um périplo pelo Portugal de Setecentos. Com o propósito de possibilitar um célere enquadramento das origens do ensino (público) da Contabilidade em Portugal, nomeadamente visando dar conta da inexistência, antes de 1759, de condiçôes que pudessem aproveitar ao desenvolvimento da Contabilidade nacional, a investigação visa também contribuir para melhorar a compreensão da envolvente contabilística adjacente à pré-história do primeiro instituto difusor do ensino da nossa especialidade.

PALAVRAS-CHAVE: Ensino da Contabilidade. História da Contabilidade. Aula do Comércio de Lisboa. Século XVIII. Manuais Portugueses de Contabilidade.

\footnotetext{
"ISCA de Coimbra. Licenciatura em Organização e Gestão de Empresas (Universidade de Coimbra); Pós-Graduação em Fconomia (Universidade de Coimbra); Mestrado em Contabilidade e Auditoria (Universidade de Aveiro); Doutorando em Contabilidade (Universidade do Minho e Universidade de Aveiro). Morada para correspondência: Miguel Gonçalves, Instituto Superior de Contabilidade e Administração de Coimbra, Quinta Agricola, Bencanta, 3040|316, Coimbra, Portugal. E-mail: mgoncalves@iscac.pt.
} 


\section{INTRODUÇÃO}

Este trabalho apresenta como principal objectivo o de dar a conhecer alguns dos problemas prévios à criação do estabelecimento pioneiro cm Portugal de ensino da Contabilidade, em 1759, fazendo-se valer, para o efeito, de uma análise da envolvente política, social, histórica e contabilística da primeira metade do XVIII século português.

A metodologia utilizada na investigação respeitou o seguinte protocolo: a) quanto aos objectivos, descritiva; b) quanto aos procedimentos, bibliográfica e quanto à abordagem do problema, qualitativa (Beuren, 2006).

Para a recolha de informação foram apenas utilizadas fontes secundárias.

No que tange à classificação deste estudo em História da Contabilidade, qualificamos a investigação como narrativa (Previts et al., 1990a) e tradicional (Stewart, 1992).

A arena na qual o estudo se irá mover no território vasto da História da Contabilidade respeita ao particular campo da História Geral da Contabilidade (American Accounting Association, 1970; Previts, 1984 ; Prcvits el al., 1990b; Carnegie e Napier, 1996).

Para além desta introdução, o texto está organizado em quatro secções. Na primeira, efectua-se uma referência, necessariamente breve, aos principais traços distintivos da origem do ensino público oficial da Contabilidade, em 1759. Na segunda secção dedica-se atenção à descrição e análise do objecto estudado, considerando-se o contexto social, cconómico e político do período antecedente à fundação da Aula de Comércio lisboeta. Ocupar-se-á a seç̧ão seguinte da discussão em torno daquilo que o país conhecia em assuntos de índole contabilística, efectuando-se, com esse propósito, uma retrospectiva da epistemologia contabilística nacional até 1759. Por último, são apresentadas algumas conclusões. 


\section{GÉNESE DO ENSINO DA CONTABILIDADE EM PORTUGAL}

A história da origem do ensino da Contabilidade em Portugal tem constituído objecto de investigações sistematizadas', sendo possível coIher informações que, incontroversamente, apontam o ano de $1759 \mathrm{e} \mathrm{a}$ Aula do Comércio de Lisboa, como referências da institucionalização do ensino (público) da Contabilidade no nosso país.

Partilhamos a opinião de que houve, efectivamente, uma importante contribuição portuguesa para a evolução do entendimento de que as matérias técnicas comerciais poderiam na realidade ser merecedoras de uma maior dedicação por parte dos poderes públicos, afastando, nas palavras de Vidal (1983: p. 73), “o velho preconceito que tanto prejudicou os estudos económicos e que levava a considerar de certo modo desprezíveis e indignas da atenção dos espíritos superiores as actividades comerciais, bem como tudo o que com elas se relacionasse."

Estamos pois, na segunda metade de Setecentos, longe do tempo em que, como nos relembra Pequito (1914: p. 7), "segundo os historiadores da Antiguidade, o exercicio do commercio e das artes industriaes era menos considerado, era até degradante". ${ }^{2}$

Procurar, no tempo e no espaço, as origens do ensino comercial oficial, implica remontar a um período do Portugal Setecentista, no qual as metamorfoses no domínio da Contabilidade, quer empresarial, quer

\footnotetext{
' A literatura contabilística tocante a esta problemática é generosa. Veja-se, a este respeito, Rodrigucs (1938), Magalhães (1945), Oliveira (1957), Felismino (1960), Gonçalves (1960), Martins (1960), Azevedo (1961), Portela (1968), Silva (1970 e 1984), Costa (1980), Vidal (1983), Cardoso (1984), Santana (1985), Lopes (1992), Tavares (1999), Caiado (2000), Marques (2000), Rodrigues (2000), Carqueja (2001 e 2002), Guimarães (2002) e, mais recentemente, Rodrigues e Gomes (2002), Rodrigues, Gomes e Craig (2003, 2004a e 2004b), Rodrigues e Craig $(2004,2005$ e 2008$)$ e Rodrigues, Craig o Gomes (2007).

As transcrições em itálico respeitam a ortografia oficial da época, opção que, a par do acatamento pela sintaxe de então, manteremos consistente ao longo de todo o trabalho. ${ }^{3}$ Na mesma linha de pensamento, Gonçalves da Silva alude a que na Grécia e em Roma Antigas, já os filósofos c oradores se compraziam em invectivar e vilipendiar as actividades cconómicas: "Platão, o divino, temia que a sua cidade ideal fosse conspurcada pelo comércio; Cícero, o eloquente, chamava-lhe "coisa sórdida" (Silva, 1948: p. 19). Acrescentamos que na mitologia romana, Mercúrio era, em simultâneo, o deus do comércio e o dos ladrões. Na mitologia grega, esse papel pertencia a Hermes.
} 
pública, foram significativa e revolucionariamente combinadas com uma importância crescente conferida à dignificação do comerciante e seu ofício.

Quando pretendemos discutir as origens da Contabilidade no nosso país, isso equivale a dizer que procuramos as fundações da Contabilidade Comercial. O problema da Contabilidade Pública é distinto e não quadra à finalidade específica do nosso texto, excepto quando as contas públicas quiseram apropriar-se do método mercantil de escrituração de livros para dotar a sua contabilidade de maior eficácia e operacionalidade, em $1761 .{ }^{4}$

Justifica-se, assim, o alinhamento de umas quantas reflexões de índole histórica, no sentido de, a seu tempo, tornarmos perceptível a envolvente económica, política, social e contabilística de uma inovação que levou à institucionalização do ensino público de Contabilidade e Comércio, em cujo programa de estudos se incluía a escrituração comercial por partidas dobradas5.

O escopo fundamental será, efectivamente, na fase inicial do nosso trabalho, fazer eeo das palavras de Serrão (1981: p. 21): “a inovação, como tal, só adquire pleno sentido desde que seja inscrita na totalidade das rotinas a que temporalmente se opõe. Por isso, [revela-se] necessário o estudo de alguns problemas prévios, sem o que corremos, com leviandade, o risco da prática do anacronismo, pecado mortal do historiador".

\footnotetext{
${ }^{4}$ Apenas nesta siłuação nos interessará as vicissitudes da Contabilidade Pública. É assunto a que voltaremos oportunamente.

"Ou "método italiano", conforme Outeiro (1869: p. 20), também designado por "método veneziano ou método de devedor e credor, expressôes que derivam da influência que nesse tempo assumiu a obra de Luca di Bartholomeu dei Pacioli de 1494 [Summa de Arithmetica, Geometria, Proportioni et Proportionalita] disseminada pela Europa“. Cf., para esta última transcrição, Amorim (1968: p. 113). Unigrafia e digrafia são expressões posteriores, como nos recorda Sá (1919: p. 18): "ficaram, portanto, só dois methodos - Partidas simples e Partidas dobradas - que Leautey e Guilbault denominaram Unigraphia e Digraphia, vocabulos que foram geralmente bem acolhidos, que teem sido adoptados por alguns tratadistas posteriores, e que nós empregaremos d'ora avante." No que toca a esta última observação (unigrafia e digrafia) é igualmente concordante a apreciação de Carqueja (2002).
} 


\section{CONTEXTO SOCIAL, ECONÓMICO E POLÍTICO}

Em sede de discussão do século XVIII em Portugal, curial se julga efectuar um périplo pela primeira metade de Setecentos, com o objectivo de percepcionarmos o ambiente de esplendor vivido na metrópole, mercê da exploração colonizadora do Brasil, maxime o seu ouro, diamantes, escravos e açúcar.

Foram estas, de acordo com Rodrigues (2000: p. 407), "as principais jóias da coroa que permitiram a D. João $\mathrm{V}$ a magnanimidade exibida no seu reinado [1706-1750]" . O mesmo autor refere que o ouro e os diamantes contribuíram para que a governação de $D$. João $V$ tivesse sido, decerto, a de maior sumptuosidade de toda a história de Portugal. Destarte, como afirma Carvalho (1982: p. 94), "surpreende que, após as descobertas das opulentíssimas riquezas minerais do solo brasileiro, transportadas para Portugal na governação de D. João V, nos encontrássemos, poucos anos decorridos, a braços com a miséria."

A época joanina imprimira grande notoriedade ao cultivo das letras $^{8}$, à magnificência das construções" e ao incremento das artes ${ }^{10}$, mas deixara o país despovoado, possuído pela Igreja, com as manufacturas arruinadas, assolado por uma severa crise cconómica, sem comércio

\footnotetext{
"Vale a pena assinalar, para o efeito, que, com base cm Azevedo (1922), entraram em Portugal, durante todo o século XVIII, pelo menos 750 toneladas de ouro provenientes das minas do Brasil, descobertas nos derradeiros anos da época de Seiscentos. A partir da década de sessenta do período Setecentista diminuíram fortemente os ingressos de ouro, não superando a tonelada e meia por ano, juntando-se-lhes, a partir de 1730 , os diamantes, calculados pelo mesmo autor em 3.000.000 de quilates, "com certa margem para o contrabando" (Azevedo, 1929: p. 365). "Os escravos necessários nas minas e nos engenhos de açúcar constituiam também uma receita da coroa - cerca de oitenta por cada um dos 400 engenhos de açúcar", como nos informa Rodrigues (2000: p. 407). ${ }^{7}$ Não se enquadra na natureza do nosso trabalho considerar o rei D. João V sob o prisma das prodigalidades e desperdícios do seu reinado. Nâo obstante, fazemo-nos valer da reflexão de Ribeiro (1871: p. 169), sobremancira elucidativa: "El-rei D. Jočo V empregou mal os immensos cabedaes dos thesouros do Esiado".

"Assim se exprime Ribeiro (idem: ibidem): "Cabe a el-rei D. Joño Vo indisputavel merecimento de [em 1720 ] haver favorecido grandemente a fundaça e os trabalhos da Academia Real da Historia Portugueza".

"Como ex libris desta época assinalamos a "construção do Convento de Mafra e do aqueduto das Águas Livres". Vide Ribeiro (idem: p. 182).

${ }^{10}$ Destaque, no campo da música, para a introdução do espectáculo de ópera italiana, verificada nos começos do reinado do soberano.
} 
nem indústrias relevantes, sem desenvolvimento agrícola, sem estradas, transportes, marinha e exército e dependente de importações, mesmo daqueles bens que rudimentares oficinas nacionais poderiam fabricar.

Para instigar a compras e consequentes pagamentos em ouro, franceses, holandeses e sobretudo, ingleses, acorriam aos portos nacionais com grande e variado número de fazendas oferecidas em excelentes condições, disto se ressentindo a indústria nacional.

Acresce que o rei, paralítico e doente, se alheara das tarefas governativas, endossando-as a homens "caducos e improdutivos" '. Cabe, assim, sublinhar que o resultado "foi uma crise de autoridade que se reflectiu em abusos da nobreza, subornos nas alfândegas, dificuldades no exercício da lei. A situação era tanto mais grave quanto tinha a acompanhá-la uma baixa considerável na produção do ouro brasileiro, assim como no mercado internacional uma diminuição de interesse pelo vinho do Porto" (Marques, Coelho e Marques, 1979: p. 17).

Em 1750, o rei D. José, sucedendo no trono a seu pai, reconhece, prontamente, a seriedade das circunstâncias em que o país se instalara e, solicitamente, constitui um elenco governamental não comprometido com o estilo de governação anterior, assente em três Secretarias de Estado $^{12}$ : Marinha e Ultramar, Negócios Interiores do Reino e Negócios Estrangeiros e Gucrra, esta última atribuída a Sebastião José de Carvalho e Melo ${ }^{13}$, uma das individualidades mais marcantes de sempre, para o bem e para o mal, da história política do nosso país e uma figura inexorávell no panorama da sociedade portuguesa de Setecentos.

Eis-nos, pois, chegados ao período "josefino-pombalino" 14 , no qual as reformas ${ }^{15} \mathrm{com}$ epicentro em Pombal, no reinado de D. José,

"A adjectivação não é nossa - extraímo-la de Carvalho (1982: p. 91 ).

12 "O primeiro governo do Rei D. José compunha-se dos seguintes Secretários de Estado: padre Diogo de Mendonça Corte-Real, Carvalho e Melo (ambos nomeados em 2 de Agosto de 1750) e Pedro da Motta (nomeado por D. João V)" (Azevedo, 1961: p. 22).

1.3 Por hábito consagrado, amiúde denominaremos Sebastião José de Carvalho e Melo por Marquếs de Pombal (ou somente Pombal), sem embargo da designação nem sempre corresponder a épocas da sua vida em que era efectivamente possuidor de tal tílulo. Com efeito, apenas em 1769 foi outorgado a Carvalho e Melo, trave mestra e figura chave do governo do monarca D. José, o título de 1. Marquês de Pombal. Agraciado com o título de 1. Conde de Oeiras foi-o em 1759.

${ }^{14}$ Expressão retirada de Torgal (1982: p. 12).

1 Contudo, nem só a interpretação da política de Pombal induz à percepção da segunda metade de Selecentos como uma época de ruptura. Muitos não imputam integralmente 
justamente cognominado O Reformador, constituem o ponto de partida mais indicado para o nosso estudo.

Nestes termos, de entre as actuações programadas e estratégicas atinentes à inversão da crítica situação global em que o país se instalara, pelo menos uma reveste-se de particular sensibilidade no contexto da Contabilidade, na medida em que, desde a fundação da Aula do Comércio, pelo Marquês de Pombal, não mais o nosso país deixou de se interessar pelo estudo da disciplina que aqui nos ocupa. ${ }^{16}$

Regra geral, a literatura contabilística (e não só) é unânime em reconhecer a dívida de gratidão que a Contabilidade e, em especial, a profissão de Guarda-Livros, assumem com o Marquês de Pombal. Veja-se, expressamente com este sentido, Ratton (1813), Beça (1918), Costa (1925), Pimenta (1934), Magalhães (1939), Brito (1949), Silva (1953), Oliveira (1957), Felismino (1960), Monteiro (1979), Costa (1980), Gomes (1982), Marques (2000), Carqueja (2002), Rodrigues e Gomes (2002), Rodrigues e Craig (2004 e 2005), Rodrigues, Gomes e Craig (2004a) e Guimarães (2005a e 2005b). Confronte-se ainda, nesta ordem de ideias, o artigo, já clássico, de Gonçalves da Silva, no qual $o$ autor, numa prosa de requintados recursos estilísticos, identifica e sugere quatro períodos da História da Contabilidade em Portugal ${ }^{17}$. O

as transfigurações ocorridas em Portugal à acção pombalina. Ver, em particular, Macedo (1951) que, na esteira de Azevedo (1909), procurou demonstrar a ausência de um programa organizado ou de um plano coerente de reformas, colocando a tónica na natureza casuistica da polílica de Pombal, como se infere pela seguinte passagem: "a actividade pombalina não foi renovadora, utilizando [antes] os organismos radicionais, assim como os métodos, ao tempo, tradicionais da monarquia portuguesa. Reorganização em Pombal quer simplesmente dizer reforço da organização existente" (Macedo, 1951: p. 38).

Í Para uma consulta de cxemplos de acções pedagógicas pombalinas tomadas no campo do ensino, a par da criação da Aula do Comércio, veja-se Oliveira (1941), Gomes (1982), Saraiva (1983), Cruzeiro (1988) e, muito particularmente, Ratton (1813), num dos parágrafos $\left(\$ 55 .^{\circ} ;\right.$ p. 211$)$ das (suas) Recordacoens que ao Conde de Oeyras feiro Marquez de Pombal, dedicou. Para melhor compreender o Marquês de Pombal e o seu tempo, consulte-se o número especial (no segundo centenário da sua morte) da Revista de História das Ideias (1982) que, em Irinta e dois testemunhos histórico-científicos, repartidos por dois tomos, coloca nas mãos do leitor importantes reflexöes acerca do significado do pombalismo.

17 Esta é, pensamos, uma abordagen pouco frequente na lileratura contabilística, pois que nos lembremos, além da cilada publicação, apenas Carvalho e Conde (2003) tentaram identificar fases e periodos para a História da Conlabilidade em Portugal, com base 
Professor taz corresponder o início do terceiro dos quatro períodos pro-postos, "à época pombalina, ou seja, uma época que, sob o ponto de vista contabilistico, se pode qualificar de revolucionária. As providências governativas respeitantes à matéria que então se tomaram, modificaram consideravelmente o panorama contabilístico português. Asseme-lharam-se a rajadas de vento fresco num ambiente miasmático" (Silva, 1984: pp. 509-510).

Finalmente, ainda nesta temática de matriz pombalina, assinalemse as comemorações da passagem do segundo centenário da fundação da Aula do Comércio, promovidas pela Sociedade Portuguesa de Contabilidade (SPC), em 1959, com realce para a romagem ao túmulo de Pombal, para ali depor um ramo de flores, em homenagem à obra do estadista. ${ }^{18}$

Adicionalmente, levanta-se ainda a questão, de saber, em traços de desenho muito rápido, o que se conhece em termos contabilísticos e em matéria do ensino da Contabilidade até ao período pombalino, época da fundação da Aula de Comércio lisboeta (1759).

\section{RETROSPECTIVA DA EPISTEMOLOGIA CONTABILÍS- TICA NACIONAL ATÉ 1759}

\subsection{Aspectos Gerais}

Indicações sobre o assunto epigrafado são-nos fornecidas por Rau (1951), Vidal (1983), Silva (1984) e Rodrigues (2000). Nessa medida, no dizer da primeira autora, "apesar do intenso contacto dos portugueses com os mercadores italianos e com os mestres e inovadores medievais que já no século XV manejavam a partida dobrada, a contabilidade portuguesa permaneceu longas centúrias realmente simples e em manifesto atraso em relação aos métodos italianos contemporâneos" (Rau, 1951: p. 399).

numa análise do inventário dos livros de Contabilidade publicados em Portugal desde o século XVIII. Cremos, honestamente, que esta é uma linha de investigação com propóm sitos de contribuições futuras interessantes, dado o escasso material publicado no nosso país por autores nacionais para uma divisão da História da Contabilidade Portuguesa. 1s Para uma exposição mais detalhada de todos os actos comemorativos no âmbito da iniciativa da SPC, consulte-se o Boletim da Sociedade Portuguesa de Contabilidade (1959: p. 9 e pp. 18-19). 
Não obstante, as escritas menos informes seriam ainda assim as da régia fazenda e as das congregações religiosas, a cargo de, respectivamente, indivíduos de fé judaica e eclesiásticos ${ }^{19}$, para tal habilitados.

Tirando uma ou outra passagem dos forais e alguns documentos ou diplomas que se salvaram, conclui Silva (1984: p. 507) que "pouco existe, ao que supomos, de algum interesse para a história da Contabilidade".

Ao nível de registos contabilísticos, sem embargo das relações comerciais que na Baixa Idade Média mantínhamos com as repúblicas italianas de Génova, Florença e Veneza ${ }^{20}$ " "o nível da técnica contabilística situava-se entre nós muito aquém do que já atingira nas mesmas" (idem: ibidem).

Sob um outro prisma, Rau (1951) dá-nos a conhecer que os livros de comércio ou de escrituração comercial deixavam de ter qualquer espécie de interesse, nas situações em que um mercador se retirava dos negócios, ou se dissolvia a companhia à qual pertencia.

Associadas a esta circunstância, a acção destruidora do tempo, a

${ }^{19}$ Em 476 d.C., com a invasão dos povos que os Romanos designavam de bárbaros, por serem rudes e desconhecedores dos primores da Civilização Romana, muitos dos progressos contabilísticos realizados pela Antiga Roma perderam-se. Neste contexto, veja-se Amorim (1968: p. 60): "nenhuma dúvida poderá restar de que a contabilidade entre os Romanos era correntemente utilizada tanto na administração pública como na administração mercantil e doméstica e já apresentava um apreciável grau de sistematização, se se atender à recuada era em que o Império Romano existiu". Com a queda do Império Romano do Ocidente, em 476 d.C., data que normalmente os historiadores fazem corresponder ao início da ldade Média, regista-se um enfraquecimento da administração pública e das instituições comerciais, bem como uma redução do tráfico comercial, associada à ruptura das vias de comunicação. Posteriormente, com a difusão do Catolicismo - cera aqui que pretendíamos chegar --., a Igreja passou a controlar o poder e a ricueza, passando desta forma a utilizar a escrita contabilistica como instrumento de controlo do seu património, distribuído principalmente por mosteiros e abadias.

20 O surto do comércio mediterrânico fez ressurgir e progredir a Contabilidade, destacando-se o desenvolvimento das cidades-Estado de Génova, Florença e Veneza. A ideia vem reforçada por Sá (1998) quando narta que a Contabilidade ganhou projecção no século XIV nas repúblicas italianas de Florença, Génova e Veneza como resultado do crescimento do comércio marítimo e de instituições bancárias. Amorim (1968: p. 70) refere-nos que só esta última, no seu período áureo, "dispunha de cerca de 3000 navios que, com os milhares de outros das restantes repúblicas italianas, sulcavam o Meditcrâneo em ambos os sentidos". Os bancos também registavam elevados indices de crescimento, pois emprestavam dinheiro para a construção de barcos. Também os seguros se desenvolvcram. 
negligência humana, as falências, as penhoras, os terramotos da primeira metade do século XVIII e, sobretudo, o de 1755, foram também factores causadores da destruição de livros comerciais.

Todavia, vale a pena referir Silva (1984), quando observa que na Exposição de História Económica de Antuérpia, realizada em 1930, foram apresentados, por Portugal, registos de comerciantes nacionais dos séculos $\mathrm{XVI}^{21}$ e XVIl.

\subsection{Regulamentação Jurídica da Escrituração Mercantil}

No que tange a este tópico de análise, nada de relevante se faz notar, na exacta medida em que as nossas Ordenações Filipinas ${ }^{22}$, do início do século XVII (1603), pouco se ocupam do assunto, como testemunha Silva (1938), prescrevendo apenas sanções para os comerciantes que não apresentassem os seus livros de Diário na situação de falência.

Realidades diametralmente opostas verificavam-se em França e Espanha, por exemplo, com as Ordenações de Colbert (Código de Savary) e as Ordenações de Bilbau, de 1673 e 1737, respectivamente.

Em França, merecem destaque os requisitos do livro diário, a sua legalização e força probatória, as disposições inerentes à conservação da correspondência e o artigo que decreta a inventariação periódica do património (Silva, 1938).

Em Espanha, a influência das Ordenações faz-se sentir no número de livros de contas, quatro, a saber: "todo lo Mercader; tratante y comerciante por mayor, deberá tener á lo menos cuatro libros de cuentas: un borrador ó manual, un libro mayor, otro para el asiento de cargazones ó facturias, y un copiador de cartas" (Silva, 1938: p. 38).

\footnotetext{
2 Por exemplo, fragmento do diário (1563-1564) de um comerciante português e fragmento de um memorial e copiador de cartas (ambos de 1555) de Pedro Lopes de Aleman, negociante português em Antuérpia.

22 Compilação jurídica resultante da reforma das Ordenações Manuelinas, como consequência do domínio espanhol (1580-1640). Como lei suprema do Reino, ficou a obra concluída ainda no tempo de Filipe 1 , que a sancionou em 1595, mas só foi definitivamente mandada observar, após a sua impressão em 1603, quando já reinava Filipe II. Embora muito alteradas, constituíram a base do direito português, até à promulgaça dos sucessivos códigos do século XIX (verbi gratia: Código Comercial de 1833, Código Civil de 1867, Código do Processo Comercial de 1895 e Código das Falências, publicado em 1899). Para ligeiras notas sobre as três ordenações do Reino, atente-se em Oliveira (1941).
} 
Gonçalves da Silva sublinha:

(i) a exigência do Razão (libro mayor) - que não tem paralelo na legislação francesa;

(ii) a imposição da correç̧ão dos erros pela prática do estorno;

(iii) os preceitos que estabelecem as diferenças entre os deveres dos pequenos e dos grandes comerciantes;

(iv) a obrigatoriedade do livro de registo de facturas e

(v) a norma que impõe aos comerciantes castelhanos por grosso, analfabetos, disporem de guarda-livros que assistam ao governo dos quatro livros escriturados segundo o método debe y ha de haber (Silva, 1970).

Ainda que não caiba aqui uma exposição mais detalhada que permita acompanhar pari passu as grandes transformações por que passou o instituto jurídico da escrituração mercantil, as análises ut supra permitem concluir que o século XVII é o momento histórico em que a legis-lação passá a considerar a relevância dos livros de Contabilidade. Marques (2006) admite que, com Colbert e a sua Ordenança de 1673, se proclama a utilidade social da Contabilidade.

\subsection{Contabilidade Pública}

No que se prende com uma análise institucional da Contabilidade Pública em Portugal, já no tempo do reinado de D. Dinis (1279-1325) existia em Portugal uma repartição que concentrava as contas dá fàzenda real, "os Contos, conforme documento de 16 de Junho de 1296 " (Rodrigues, 2000: p. 366).

Os Contos, mais tarde a Casa dos Contos, funcionavam como uma repartição onde se recenseavam, centralizavam e fiscalizavam as contas da fazenda pública que, como se sabe, à época, eram confundidas com as do monarca. Entre outros funcionários, havia nos Contos certo número de contadores ${ }^{23}$ e seus auxiliares - os escrivães. As funções dos contadores passavam essencialmente pelo controlo.

"Destruída pelo terramoto de 1755", conforme assegura Rodrigues (2000: p. 374), os incêndios que se the seguiram arrasaram quase por

${ }_{23}$ Este é o termo antigo original para Contabilista. No entanto, "como se começou a conar o gaz e a agua por aparelhos assim denominados, pareceu-nos mais proprio empregar Contabilista como equivalente ao vocabulo francês Comptable" (Sá, 1926: p. 31). 
completo o edifício onde funcionavam os Contos e praticamente toda a sua documentação, provocando uma desordem nos serviços que precipitaria a sua dissolução. ${ }^{24}$

Extinta em 1761, a Casa dos Contos registou abusos, incompetências e fraudes, motivadas pelos transversais problemas da sociedade portuguesa de então - corrupção e analfabetismo ${ }^{25}$.

Esta questão convoca, aliás, uma outra, que se prende com o siste-ma de escrituração utilizado nos livros da repartição contista.

Ora, é sabido que a utilização da partida simples, em confronto com a partida dobrada ${ }^{26}$, configura um método de registo inexacto $\mathrm{e}$ potenciador de fraude que, além do mais, impossibilita a conferência de contas.

No que se prende com o processo das partidas dobradas, vale a pena dizer, seguindo de perto Pequito (1875: p. 142), que "o systema das partidas dobradas foi primeiramente chamado methodo italiano, porque nas cidades de Veneza, Genova, Florença, e outras da Italia, foi onde elle primeiramente se usou. Depois foi-lhe dada a denominação de partidas dobradas, porque, analysando-se que em cada operação havia dois factos inseparaveis - um debito não póde existir sem um credito e vice-versa - e comparando-se os dois systemas viu-se que por este ultimo se descreviam esses dois factos. E como o primeiro ainda não tinha denominação ficou-se chamando partidas simples".

Quanto às vantagens do funcionamento das partidas duplas sobre as partidas simples (ou singelas), atentemos nos argumentos do mesmo autor. Com efeito, Pequito (1875) dedica umas quantas linhas do seu Curso de Contabilidade Commercial a discutir os benefícios da utiliza-. ção da partida dobrada. Reproduzamos, no essencial, o epílogo da sua fundamentação:

\footnotetext{
24 Para um exame rigoroso do que foi a Casa dos Contos, veja-se o trabalho de Rau (1951), ilustre historiadora desta repartição. Para um estudo sintético, consulte-se Ro. drigues $(2000)$.

${ }^{25}$ A primeira informação sobre analfabetismo a nivel nacional (Continente e Ihas Adjacentes) é de 1878 , data do primeiro censo oficial. Apenas $14,3 \%$ da população portuguesa sabia ler e escrever (Carvalho, 2001). Mais de cem anos antes, em meados do XVIIl século português, podemos perspectivar que este número seria com certeza substancialmente inferior, para grande vergonha nacional.

26 Sá (1998: p. 44) utiliza a feliz definição: "a partida dobrada mais não é do que o re-. gisto de um facto patrimonial em sua causa e efeito".
} 
"Não obstante a superioridade reconhecida do systema das partidas dobradas ao das partidas simples, ainda este tem muitos apologistas que censuram aquelle, dizendo que por elle se escreve o dobro do que é preciso. Responderemos a estes apologistas pelas palavras de De Granges, dizendo-lhes que pelas partidas dobradas se descreve tudo o que diz respeito a cada operação, logo escreve-se o que é preciso, e que pelas partidas simples se descreve metade do que diz respeito a cada operação, e portanto escreve-se metade do que se deveria escrever" (Pequito, 1875: p. 142).

Consequentemente, não deve surpreender que, trabalhando a Contabilidade Pública com a partida simples, até $1761^{27}$, os relatos de devassidão, descrença e desmoralização do sistema tivessem surgido em catadupa. Neste particular, por exemplo, de grande relevância é, uma vez mais, a análise e o testemunho incluídos em Ratton (1813), sobre o desleixo e a incúria que generalizadamente grassavam na Administração Pública portuguesa.

Com a oficialização do Erário Régio - em substituição da Casa dos Contos -, promulgada por carta de lei de 22 de Dezembro de 1761 , procurou o Governo de Pombal controlar e tornar mais eficiente a arrecadação do dinheiro público.

As partidas dobradas cram entendidas como um meio para legitimar a nova organização, pois eram consideradas o melhor método para. a administração das contas públicas (Gomes, 2007). Nestes termos, Corrêa (1930), Martins (1960), Portela (1968) e Rodrigues (2000), defendem que Pombal, em 1759, com a implementação da Aula do Comércio, tinha já em mente a formação e preparação de profissionais habilitados para organizar e trabalhar nessa importante repartição pública.

\subsection{Manuais Portugueses de Contabilidade}

Pode levantar-se também um ponto de discussão em torno dos compêndios de Contabilidade, já que, nas palavras de Silva (1984: p. $509)$, "é deveras surpreendente que no período que abarca os séculos XVI, XVIIl e grande parte do XVIII, nenhum português cometesse a tarefa de escrever ou traduzir um manual de Contabilidade".

27 Ano da criação do Erário Régio e da introdução em Portugal por Pombal da partida dobrada, na sua escrituração, como novo método contabilístico de administração das finanças públicas. 
Neste sentido, uma vez aberto o filão com Luca di Bartholomeu dei Pacioli em 1494 com a Summa, espécie de rastilho para o desencadeamento das actividades publicitárias no domínio da Contabilidade, inverosímil seria esperar-se que, durante tão largo espaço de tempo, não tenham chegado a Portugal exemplares das obras que entretanto se publicavam no estrangeiro inspiradas no De Computis et Scripturis, cabendo aqui destacar, com base em Marques (2000: p. 72), "as obras de Tagliente (1524), Gottlieb (1531), Cardano (1539), Manzoni (1534), Oldcastle (1543), Ympyn (1543) e Savonne (1567)".

Na oportunidade, assinale-se que a obra de Paciolo ${ }^{28}$ não versava exclusivamente sobre matérias de Contabilidade, mas sim sobre Aritmética, Álgebra e Geometria, disciplinas âncora da sua formação, a par da Teologia, visto tratar-se de um frade pertencente à Ordem dos Franciscanos. O professor Gonçalves da Silva apelidava-o de uma verdadeira "cátedra ambulante" (Silva, 1948: p. 16) e, na realidade, a sua formação polivalente e multidisciplinar é a de um intelectual renascentista e a de um docente respeitado e disputado pelas cortes e universidades mais famosas que buscavan as suas lições c conferências.

Na época, era usual resumir-se num compêndio algumas das partes que compunham uma ciência ou ramo de conhecimentos. Paciolo fê-lo, portanto, para a Matemática.

Na opinião de Gonçalves (2007: p. 39), "a obra continha algumas originalidades relativas a cálculo de probabilidades, equações exponenciais e logaritmos neperianos".

Incluido na Summa de Paciolo, a Distinção IX, Tratado XI - Tractactus Particularis de Computis et Scripturis - comporta trinta e seis capítulos, sendo que, na visão de Amorim (1968: p. 76) "o mais importante é, sem dúvida, o último, por ser aí que Paciolo condensa os

\footnotetext{
2. Segundo tradição na Baixa Idade Média italiana, Paciolo emprega-se quando se cita apenas o sobrenome. Quando se fala no nome completo diz-se Luca Pacioli (o "o" é substituído pelo "i" e acrescenta-se o primeiro nome). Em todo o caso, Paciolo também por vezes vem referenciado, entre outros diversos nomes, por Luca di Borgo, em homenagem ao seu local de nascimento, em Borgo de Sansepulcro, em 1447, hoje uma comuna pertencente à província de Arezzo, região da Toscana, ltália. Para uma revisão da vida e obra de tão famoso autor veja-se Silva (1948), Sá (1993), Hernández Esteve (1994), Lamoroux (1994), Sousa (1995), Conçalves (2007) e Tua Pereda (s/d). Para uma traduçâo castelhana comentada e anotada da primeira obra impressa de Contabilidade, contendo também uma reprodução fotográfica do trabalho de Luca Pacioli, ver Hernández listeve (1994).
} 
diferentes tópicos da sua exposição do sistema de Contabilidade por partidas dobradas". ${ }^{29}$

É admissível que alguns compêndios de Contabilidade tivessem chegado a Portugal por intermédio de comerciantes estrangeiros radicados nas cidades de Lisboa e do Porto, ainda que, no pensamento de Silva (1984), a prova seja difícil de reunir.

A propósito da introdução da partida dobrada na Europa Ocidental podem ainda colocar-se algumas questões a que fazemos, em seguida, uma breve alusão. ${ }^{30}$ Assim:

(1) numa altura em que na Europa, mais concretamente nos círculos italiano, inglês, flamengo, alemão, espanhol c francês, com a impressão das obras de Luca Pacioli (1494), Hugh Oldcastle $^{31}$ (1543), Jan Ympyn ${ }^{32}$ (1543), Wolfgang Scheweicker ${ }^{33}$ (1549), Antich Rocha ${ }^{34}$ (1565) e Pierre de Savonne ${ }^{35}$ (1567), respectivamente, a partida dobrada à italiana assumia o papel de protagonista na literatura contabilística;

(2) numa época em que já se escrevia sobre lançamentos compostos e complexos ${ }^{36}$

${ }^{20}$ Em Silva (1984) é possivel encontrar a indicação que da primeira edição da Summa possui a biblioteca da Universidade de Coimbra um exemplar.

30 Abaixo, os itens (1), (2), (3) e (4) - e adjacentes notas de fim de página - seguem, no seu essencial, as argumentaçôes de Amorim (1968), Monteiro (1979) e Cravo (2000), formalizadas nas conclusões de Gonçalves (2007: pp. 47-51). Nesta ordem de ideias, para uma interessante e didáctica viagem sobre a repercussăo directa da obra de Luca Pacioli nos círculos contabilísticos europeus ocidentais (ltália, lnglaterra, Países Baixos, Alemanha, França, Suíça, Espanha, Portugal) estude-se Amorim (1968: pp. 113 127), Cravo (2000: pp. 34-37) e Monteiro (1979: pp. 68-75).

31 Tratadista britânico autor da mais antiga obra de Contabilidade inglesa, introduzindo assim na Grã-Bretanha a partida dobrada italiana.

32 Primeiro autor a publicar uma obra em flamengo. Monteiro (1979: p. 71) assume tratar-se de uma obra de "grande clareza didáclica, com conceitos originais, contendo uma verdadeira monografia contabilística". Refere ainda que se trata de uma das obras mais conhecidas da litcratura contabilística do século XVI, alé porque fó traduzida para o francês, sendo inclusivamente a primeira obra contabilística escrita nessa língua ${ }^{33} \mathrm{O}$ seu principal contributo foi a conta colectiva de Devedores e Credores.

34 "Professor da Universidade de Barcelona", de acordo com Antunes (1958: p. 21 ).

3. Publica a primeira obra de Contabilidade francesa em que divulga a partida dobrada, mas já antes o tratado de Jan Ympyn fora traduzido para o francês, obra originalmente escrita em flamengo.

36 Valentin Mennher foi em 1520 o primeiro autor a versar sobre lançanentos comple 
(3) num período em que, dentro da Contabilidade, obras de especialização foram irrompendo, como a primeira de Contabilidade Industrial em 1601, em Itália, e a primeira de Contabilidade Pública $^{37}$, nos Países Baixos e

(4) num tempo em que inclusivamente já havia quem se balanceasse por terrenos da História da Contabilidade ${ }^{38}$,

Em Portugal, como bem conclui Marques (2000: p. 110), "a falta de compêndios de Contabilidade, originais ou traduzidos, foi, ao mesmo tempo, causa e efeito do atraso português nesta matéria, relativamente aos países europeus".

Mau grado o terramoto de 1755 , após o qual Portugal terá perdido um património bibliográfico de primeira ordem, espanta-nos de facto a demora do aparecimento de livros de Contabilidade portugueses, porquanto observávamos já a existência da imprensa ${ }^{39}$, registávamos uma intensa actividade comercial relacionada com os Descobrimentos ${ }^{40}$ e havíamos vivido em União lbérica sessenta anos, entre 1580 e $1640^{41}$.

xos e compostos. O tratado de Frei Luca Pacioli apenas continha lançamentos simples. Segundo Anorim (1968), a partida dobrada consubstancia-se em quatro fómulas digráficas ou cm quatro lançamentos digráficos, a saber: (i) um débito = um crédito -lançamento simples; (ii) um débito = vários créditos - lançamento composto; (iii) um crédito $=$ vários débitos - lançamento composto e (iv) vários débitos $=$ vários créditos - lançamento complexo.

${ }^{37}$ No início do século XVII, Simon Stévin, defende, numa obra inticulada "Contabilidade do Príncipe", o uso das partidas dobradas na Contabilidade Pública dos Países Baixos, proposta que, segundo Carqueja (2002: p. 16), "não teve acolhimento". Vlaemminck (1961) assinala-nos que se trata do primeiro autor a escrever sobre Contabilidade Pública. 38 Seguindo a Cravo (2000: p. 37), Claude Irson no século XVII (1678) foi o primeiro autor a efectuar uma tentativa de estabelecer a História da Contabilidade.

39) De acordo com José V. Pina Martins, professor, investigador e bibliófilo de autoridade extraordinária no estudo do Humanismo Renascentista, o primciro incunábulo português intitula-se Tralado de Confissom e foi impresso em Chaves, em Agosto de 1489. O único exemplar (existente na Biblioteca Nacional de Portugal) foi por si descoberto em 1965. Desconhece-se o autor, devido ao facto de lhe laltar a página de rosto. C.f. Marlins (2007).

40 "Em particular, o destaque, no início do século XVI, da feitoria portuguesa na Flan" dres, região onde a Contabilidade foi objecto de livros muito eedo". Conferir Carqueja (2002: p. 29).

${ }^{4}$ Recordemos que é de 1565 o livro de Antich Rocha publicado em Espanha. O segundo manual técnico contabilístico eastelhano é de 1590 da autoria de Bartolomé Salvador de Solórzano. Este autor publicou a primeira obra de Contabilidade genuinamente espanhola, porquanto o tratado de Rocha não passava de uma tradução para o castelhano do 
Em consequência, em Portugal apenas são conhecidas obras de Contabilidade do século XVIII, inspiradas já pela atmosfera pombalina, sendo João Baptista Bonavie o primeiro autor, em 1758, a versar sobre matérias afins à Contabilidade. A obra apresentava o pomposo título:

Mercador exacto nos seus livros de contas, ou methodo facil para qualquer mercador e outros arrumarem as suas contas com a clareza necessária, com seu Diario, pelos princípios das partidas dobradas, segundo a determinação de Sua Magestade. ${ }^{42}$

A obrigatoriedade de escrita por partidas dobradas aos comerciantes falidos ${ }^{43}$ pode ter motivado Bonavie à redacção e impressão do Mercador Exacto, sugere-nos Martins (1960).

Um comentário concordante é-nos esboçado por Pequito (1875), ao referir que a expressão determinação de Sua Magestade, alude a um alvará de 13 de Novembro de 1756 que mandava observar, no que concerne a homens de negócio falidos, os preceitos das partidas dobradas nos seus livros de escrituração. Importa ainda esclarecer que, na opinião de Silva (1948), a despeito de haver registado três edições, em 1758, 1771 e 1779, não passa o compêndio de medíocre adaptação de uma obra de Matthieu de la Porte ${ }^{44}$.

Apesar de eméritos professores - como Lopes Amorim, Gonçalves da Silva, Rogério Fernandes Ferreira, Hernâni Olímpio Carqueja e Pires Caiado - e operosos publicistas da História da Contabilidade - como Benavente Rodrigues e Everard Martins -, classificarem a obra de Bonavie como pioneira em Língua Portuguesa, Monteiro $(1979)^{45} \mathrm{e}$ Rodrigues (2000) referem a existência de um livro publicado (em 1706)

manual de Valentin Mennher. Sobre este assunto, Silva (1948) e Hernández Esteve (1981).

42. Sobre o primeiro compêndio de Contabilidade que se publicou em Portugal ver Pequito (1875: p. 143), Silva (1948: p. 22; 1970: pp. 97-100 e 1984: p. 510), Martins (1960: p. 16), Amorim (1968: p. 122), Caiado (2000: p. 2), Carqueja (2002: p. 30) c Guimarães (2005a: pp. 519-524). Para um ensaio mais completo sobre a bibliografia nacional de manuais de Contabilidade, consultar, em particular, Nunes (1933), Martins (1944), Marques (2000), Carqueja (2002) e Guimarães (2005a). Para uma análise mais refinada do primeiro livro português de Contabilidade, veja-se Silva (1948a; 1953) e Guimarães (2005a). Na época de Pombal, mais duas obras surgiram em língua portuguesa; uma, de autor anónimo, editada em Turim, em 1764 e outra do primeiro lente da Aula de Comércio, João Henrique de Sousa, em 1765.

43 "Pela carta de lei de 13 de Novembro de 1756 - parágrafo XIV" (Martins, 1944: p. 263). ${ }^{44}$ No entanto, Stevelinck (1970: p. 63), apud Carqueja (2002: p. 17), anota que a obra de Bonavie "est fortment inspiré de Bertrand-Francois Barrême".

${ }^{45}$ Com base em Vlaemminck (1961). 
em Amesterdão de autoria de Gabriel de Souza Brito, possivelmente um judeu português de ascendência espanhola, intitulado Norte Mercantil e crisol de contas dividido em três livros, nos quais se tratam por modos muito fáceis... e a declaração do livro de caixa e seu manual de contas de Mercadores.

Indicavam ser este, portanto, o primeiro livro português de Contabilidade.

Ainda muito recentemente, Guimarães (2005a) colocava a hipótese de haver uma edição portuguesa, mas hoje a dúvida está desfeita, porque o tratado está redigido em castelhano e denomina-se

Norte mercantil y crisol de cuentas dividido en tres livros, en los cuales se tratan por modos muy faciles, y breves de la arithmetica y especulativa com todas las reglas, y secretos de essa arte, y de os giros de cambios de una plaça a outra, y las monedas corrientes, que ay en Europa, y fiera della, y la declaracion del livro de caxa y su manual de cuentas de mercaderes.

Vale a pena dizer, para concluir, que se trata de um plágio de obras espanholas anteriores, como atesta Hernández Esteve (1985). Em bom rigor, o mesmo autor, num artigo escrito (quatro anos antes, refere já a existência da obra em castelhano, como se confirma pela seguinte passagem: "antes de Sebastián de Jocano y Madaria escribieron de Contabilidad en esta centuria Gabriel de Souza Brito, um judio portugués afincado em Amsterdam, donde enseñaba, que publicó en castellano su Norte Mercantil en 1706" (Hernández Esteve, 1981: p. 21).

\section{CONCLUSÃO}

Procurámos, ao longo do texto, dar nota dos principais aspectos envolvidos na problemática da pré-institucionalização do ensino da Contabilidade em Portugal, diligenciando no sentido de abordar a contextualização económica, política, social e, sobretudo, contabilística, que presidiu à criação da Aula de Comércio da capital.

A pré-históric do primitivo estabelecimento de ensino de Contabilidade e Comércio do nosso país está repleta de acontecimentos, envolventes e condicionantes que, interligados no Portugal Setecentista, proporcionaram condições e terreno fértil para a fundação em 1759 da Aula de Comércio de Lisboa. 
Até esta data, não estava garantida a legitimação da nossa área de saber, nem por iniciativa estatal, com implementação de infra-estruturas escolares, nem por cooperação com empreendedores parliculares. Em poucas palavras, não existiam institutos nos quais se pudessem transmitir c partilhar conhecimentos, nem tão pouco havia uma política de formação de quadros, da qual fizesse parte a escrituração comercial.

Sintomático também deste espírito (lamentavelmente) ausente da Contabilidade, é a entrada tardia de Portugal (1758) no grupo dos países com manuais impressos de escrituração que fizessem menção a aspectos contabilísticos.

Neste sentido, a Aula de Comércio, como actuação estratégica, inovadora e programada do poder polílico, constituiu o instrumento promotor da oficialização do ensino da Contabilidade em Portugal e, mais do que isso, terá contribuído de forma decisiva para o reconhecimento social da profissão de Guarda-Livros.

\section{REFERENCIAS}

AMERICAN ACCOUNTING ASSOCIATION (1970) - Committee on Accounting History, Accounting Review, suplemento, vol. XLV, pp. 53-64.

AMORIM, Jaime Lopes (1968) - Digressão através do vetusto mundo da Contabilidade. Porto: Livraria Avis.

ANTUNES, Francisco Xavier (1958) - Preparação escolar e formação profissional do contabilista e do perito contabilista. Lisboa : Sociedade Portuguesa de Contabilidade.

AZEVEDO, J. Lúcio de (1909) - O Marquez de Pombal e a sua época. Lisboa: Livraria Clássica Editora de A. M. Teixeira \& $\mathrm{C}^{\mathrm{M}}$.

AZEVEDO, J. Lúcio de (1922) - O Marquez de Pombal e a sua época. 2." Edição com emendas. Rio de Janeiro : Annuário do Brasil ; Lisboa : Seara Nova c Porto: Renascença Portuguesa.

AZEVEDO, J. Lúcio de (1929) - Épocas de Portugal Económico : esboços de História. Lisboa : Livraria Clássica Editora.

AZEVEDO, Mário da Conceição (1961) - A Aula do Comércio, primeiro estabelecimento de ensino téenico profissional oficialmente criado no Mundo. Lisboa : Escola Comercial Ferreira Borges.

BEÇA, Humberto (1918) - O Ensino Comercial em Portugal. Porto : Escola Secundária de Comércio.

BEUREN, Ilse Maria et al. (2006) - Como claborar trabalhos monográficos em Contabilidade, 3." ed.. São Paulo: Editora Allas. 
BOLETIM DA SOCIEDADE PORTUGUESA DE CONTABILIDADE (1959) - "Vida Associativa: Il Centenário da Aula do Comércio". N." 21/22, ano 6.', Outubro de 1959/.Janeiro de 1960, p. 9 e pp. 18-19.

BRITO, António Tomé de (1949) - "Depoimento". In Vantagens para a Contabilidade da Regulamentação Profissional dos Técnicos de Contas (1953) -. depoimento proferido em 28 de Abril de 1949 nas sessões promovidas pela SPC. Lisboa: Sociedade Portuguesa de Contabilidade. pp. 71-78.

CAIADO, António Pires (2000) -- "The Teaching of Accounting in Aula do Comércio (1759-1844)“. Comunicação apresentada no 8. Congresso Mundial de Historiadores de Contabilidade, Academy of Accounting Historians. pp. $1-9$.

CARDOSO, José Luís (1984) - "Uma 'Notícia Esquecida': o Ensino da Economia na Aula do Comércio". Estudos de Economia, vol. V, n." 1, OutDez. pp. 87-112.

CARNEGIE, G. D. e NAPIER, C. J. (1996) “Critical and Interpretative Histories: Insights into Accounting's Present and Future through its Past". Accounting, Auditing and Accountability Journal, vol. 9, n. ${ }^{\circ}$, pp. 7-39.

CARQUEJAA, Hernâni O. (2001) - "Entrada da Contabilidade no ensino oficial, e depois no ensino superior". Jornal do Técnico de Contas e da Empresa, n. ${ }^{\circ} 424$, Jan. pp. 362-364.

CARQUEJA, Hernâni O. (2002) - Do saber da profissão às doutrinas da Academia. Separata anexa à Revista de Contabilidade c Comércio, n." 234 235, vol. LIX.

CARVALHO, José Manuel Matos de ; CONDE, Maria de Fátima Travassos (2003) - "Fases e períodos da História da Contabilidade em Portugal: uma primeira tentativa de identificação". Revista de Contabilidade e Comércio, n." 233, vol. L.IX. pp. 57-84.

CARVALHO, Rómulo de (1982) - "O recurso a pessoal estrangeiro no tempo de Pombal". Revista de História das Ideias. O Marquês de Pombal e o seu tempo, Tomo I. Coimbra : Instituto de História e Teoria das Ideias. Faculdade de Letras. pp. 91-115.

CARVALHO, Rómulo de (2001) - História do ensino em Portugal: desde a fundação da nacionalidade até ao tim do regime de Salazar-Caetano. 3." ed.. Lisboa : Fundação Calouste Gulbenkian.

CORREA, Francisco António (1930) - História Económica de Portugal. Volume II. Lisboa : Tipografia da Empresa Nacional de Publicidade.

COSTA, Carlos Baptista da (1980) --- "O Ensino da Contabilidade em Portugal - a necessidade de uma Licenciatura em Contabilidade“". Revista de Contabilidade e Comércio, n. ${ }^{\circ} 176$, vol. XLIV. pp. 389-404.

COSTA, Laurindo (1925) - A evolução do ensino profissional: séculos XIX a XX. Porto : Imprensa Nacional.

CRAVO, Domingos José da Silva (2000) - Da Teoria da Contabilidade às Estruturas Conceptuais. Aveiro: Instituto Superior de Contabilidade e Administração de Aveiro. 
CRUZEIRO, Maria Eduarda (1988) - "A reforma pombalina na História da Universidade". Análise Social, vol. XXIV, n." 100. pp. 165-210.

FELISMINO, Aureliano (1960) - No duplo centenário da Aula do Comércio. Lisboa : [s.n.].

GOMES, Delfina Rosa da Rocha (2007) - Accounting change in central Government: the institutionalization of double entry bookkeeping at the portuguese Royal Treasury. Braga : Universidade do Minho; Escola de Economia e Gestão. Dissertação de Doutoramento em Ciências Empresariais, especialização em Contabilidade.

GOMES, Joaquin Ferreira (1982) - "O Marquês de Pombal criador do ensino primário oficial". Revista de História das Ideias. O Marquês de Pombal e o seu tempo, Tomo II. Coimbra : Instituto de História e Teoria das Ideias. Faculdade de Letras. pp. 25- 41.

GONÇALVES, Júlio César da Silva (1960) -- A Aula do Comércio. Lisboa: [s.n.].

GONÇALVES, Miguel (2007) - História do Pensamento Contabilístico: prelecç̧ões feitas ao Curso de Contabilidade e Auditoria - Lições da parte descritiva da disciplina. 58 p. Monografia efectuada no âmbito da docência da disciplina de História do Pensamento Contabilístico, ano lectivo 2006/2007, $2 .^{\circ}$ semestre. Acessível no Instituto Superior de Contabilidade e Administração de Coimbra. Coimbra. Portugal.

GUIMARÃES, Joaquim Cunha (2002) - “Centenário (1902-2002) da Escola Prática Comercial Raul Dória“. Revista da Câmara dos Técnicos Oficiais de Contas, 11." 33, Dezembro. pp. 20-25.

GUIMAR ÃES, Joaquim Cunha (2005a) - História da Contabilidade em Portugal: reflexões e homenagens. Lisboa : Áreas Editora.

GUIMARÃES, Joaquim Cunha (2005b) -- "Marquês de Pombal: o 'farol" da Contabilidade em Portugal". Jornal de Contabilidade, n." 342, Setembro, Boletim do Centro de Estudos de História da Contabilidade. Lisboa : Associação Portuguesa de Técnicos de Contabilidade. pp. 1-2.

HERNÁNDEZ ESTEVE, Esteban (1981) - "Contribucion al estudio de la historiografia Contable en España". Revista Espanola de Financiación y Contabilidad, vol. X, n. 34 , Enero-Abril. pp. 11-30.

HERNÁNDEZ ESTEVE, Esteban (1985) - "A Spanish Treatise of 1706 on Double-Entry Bookkeeping: 'Norte Mercantil y Crisol de Cuentas', by Gabriel de Souza Brito". Accounting \& Business Research, vol. 15, issue 60, Autumn. pp. 291-296.

HERNÁNDEZ ESTEVE, Esteban (1994)-- Luca Pacioli: de las cuentas y las escrituras. Madrid : Asociacón Española de Contabilidad y Administración de Empresas (AECA).

LAMOROUX, Fernando Martin (1994) "La influencia de Pacioli durante el siglo XVI". Revista de Contabilidade e Comércio, n.” 203. pp. 297-320. 
LOPES, Fernando da Conceição (1992) - "História da Contabilidade - A Aula do Comércio: primeira escola de gestores em Portugal. Jornal do Técnico de Contas e da Empresa, n. ${ }^{\circ} 320$, Maio. pp. 127-128.

MACEDO, Jorge Borges de (1951) - A Situação económica no tempo de Portugal. Porto : Livraria Portugália.

MAGALHÃES, Alfredo Coelho de (1939) -.. "Os Institutos Comerciais e a formação do Contabilista". Revista de Contabilidade c Comércio, n. ${ }^{\circ} 27$, Jul-Set. pp. 235-242.

MAGALHÃES, Alfredo Coelho de (1945) - Relatório: Instituto Comercial do Porto 1933-1945 - da actividade cultural e educativa do Instituto e da situação dos seus diplomados. Porto : Imprensa Moderna $\mathrm{L}^{\text {da }}$.

MARQUES, A. H. Oliveira ; COELHO, Anaiza Peres e MARQUES, Adelaide Salvador Marques (1979) - História. Il Volume. Colecção Textos Pré-Universitários, n. ${ }^{\circ}$ 22. Ministério da Educação - Secretaria de Estado do Ensino Superior. Lisboa : Editorial do Ministério da Educação.

MARQUES, Maria da Conceição da Costa (2000) - "A evolução do pensamento contabilístico nos séculos XV a XIX“. Jornal do Técnico de Contas e da Empresa, n. ${ }^{\circ} 414$, Março e n. ${ }^{\circ} 415$, Abril. pp. 69- 72; pp. 107-111.

MARQUES, Maria da Conceição da Costa (2006) - Diapositivos para aulas de História do Pensamento Contabilístico. Trabalho efectuado no âmbito da disciplina de História do Pensamento Contabilístico, ano lectivo 2006/2007, 1." semestre. Acessivel no Instituto Superior de Contabilidade e Administração de Coimbra. Coimbra. Portugal.

MARTINS, Everard (1944) "Ensaio de bibliografia portuguesa de Contabilidade". Revista de Contabilidade e Coméreio, n. ${ }^{\text {s }} 47$ e 48 , Jul.-Dez. pp. 260-278.

MAR'TINS, Everard (1960) - A Aula do Comércio: 1759. Lisboa : [s.n.]

MARTINS, J. V. de Pina (2007) - Histórias de livros para a história do Livro. Lisboa : Fundação Calouste Gulbenkian.

MONTEIRO, Martim Noel (1979) - Pequena História da Contabilidade. 2." edição. Lisboa : Europress.

NUNIS, Arnaldo (1933) - "Elementos para a História da Contabilidade". Revista de Contabilidade e Comércio, n. ${ }^{\circ} 4$, vol. I, Out.-Dez. pp. 279-282.

OLIVEIRA, Camilo M. de (1941) - Origem e progresso da Escola Comercial de Oliveira Martins. Porto : Imprensa Moderna, Ltd..

OLIVEIRA, Eduardo Maria Baptista de (1957) - "Evolução do ensino técnico comercial em Portugal". Revista de Contabilidade e Comércio, n. ${ }^{\circ} 97$, Jan-Mar. pp. 62-71.

OUTEIRO, José Maria d'Almeida (1869) - Estudos de escripluração mercantil por partidas dobradas em matéria de mercadorias. 2 ." ed. revista e aumentada. Porto: 'Typographia Lusitana.

PEQUITO, Rodrigo Affonso (1875) - Curso de Contabilidade Commercial. Lisboa: Livraria Pacheco \& Carmo. 
PEQUITO, Rodrigo Affonso (1914) - A Instrucção Comercial Superior: Discurso proferido na Sessão Solemne de Abertura de aulas do Instituto Superior de Commercio em 29 de Novembro de 1913. Lisboa : Typographia "A Editora Limitada".

PIMENTA, Pedroso (1934) - "O Marquez de Pombal regulamentou as profissões de Técnicos de Contas". Revista de Contabilidade e Comércio, n. ${ }^{\circ}$ 8, vol. 11. Out.-Dez. pp. 289-295.

PORTELA, António Farinha (1968) - "A evolução histórica do ensino das Ciências Económicas em Portugal". Análise Social, vol. VI, n." "22-23-24. pp. 787-836.

PREVITS, G. J. (1984) -“Methods and Meanings of Historical Interpretation for Accountancy". The Accounting Historians Notebook, Fall.

PREVITS, G. J., PARKER, L. D. e COFFMAN, E. N. (1990a) - "Accounting History: Definition and Relevance“. Abacus, vol. 26, n.. 1, pp. 1-16.

PREVITS, G. J., PARKER, L. D. e COFFMAN, E. N. (1990b) -"An Accounting Historiography: Subject Matter and Methodology". Abacus, vol. 26, n." 2, pp. 136-158.

RATTON, Jacome (1813) - Recordacoens de Jacome Ratton sobre occurrencias do seu tempo em Portugal, durante o lapso de sessenta e tres annos e meio, alias de Maio 1747 a Setembro de 1810 . Londres: Impresso por H. Bryer.

RAU, Virgínia (1951) - A Casa dos Contos. Coimbra : Faculdade de Letras da Universidade de Coimbra - Instituto de Estudos Históricos Dr. António de Vasconcelos.

REVISTA DE HISTÓRIA DAS IDEIAS (1982) - O Marquês de Pombal e o seu tempo, Tomo I e II. Coimbra : Instituto de História e Teoria das Ideias. Faculdade de Letras.

RIBEIRO, José Silvestre (1871) -... Historia dos estabelecimentos Scientificos, Litterários e Artisticos de Portugal nos successivos reinados da monarchia. 'Tomo ll. Lisboa: Typographia da Academia Real das Sciencias.

RODRIGUES, Lúcia Lima e GOMES, Delfina (2002) - "Evolução da profissão dos TOC em Portugal: do Marquês de Pombal até aos nossos dias". Jornal de Contabilidade; n. 302, Maio. pp. 131-141.

RODRIGUES, Lúcia Lima ; GOMES, Delfina e CRAIG, Russell (2003) -.- "Aula do Comércio: primeiro estabelecimento de ensino técnico profissional oficialmente criado no mundo?". Revista da Câmara dos Técnicos Oficiais de Contas, n. ${ }^{\circ} 34$, Janeiro. pp. 46-54.

RODRIGUES, Lúcia Lima e CRAIG, Russell (2004) - "English mercantilist influences on the foundation of the portuguese School of Commerce". Allantic Economic Journal, vol. 32, n. ${ }^{\circ} 4$. pp. 329-345.

RODRIGUES, Lúcia Lima; GOMES, Delfina e CRAIG, Russell (2004a) -- "Corporativismo, Liberalismo e a profissão contabilística em Portugal desde 175.". Revista da Câmara dos Técnicos Oficiais de Contas, $11 .^{\circ} 46$, Janeiro. pp. 24-39. 
RODRIGUES, Lúcia Lima ; GOMES, Delfina e CRAIG, Russell (2004b) - "Portuguese School of Commerce, 1759-1844: a reflection of the "Enlightenment" ". Accounting History, vol. 9, November. pp. 53-71.

RODRIGUES, Lúcia Lima e CRAIG, Russell (2005) ... "Influências mercantilistas inglesas na criação da Aula do Comércio em 1759". Revista da Câmara dos Téenicos Oficiais de Contas, n." 62, Maio. pp. 22-33.

RODRIGUES, Lúcia Lima ; CRAIG, Russell e GOMES, Delfina (2007) -- "State intervention in commercial education: the case of the portuguese School of Commerce, 1759. Accounting History, Vol. 12, n." 1. doi: 10.1177/1032373207072808. pp. 55-85.

RODRIGUES, Lúcia Lima e CRAIG, Russell (2008) -- "Teachers as servants of State ideology: Sousa and Sales, portuguese School of Commeree, 1759-1784". Critical Perspectives on Accounting. doi:10.1016/j. cpa.2007.11.001. pp. 1-20.

RODRIGUES, Manuel Benavente (2000) - "Carta de Lei de 22 de Dezembro de 1761 sobre a exlinção dos Contos e a criação do Real Erário". Revista de Contabilidade e Comércio, n." 226, vol. LVII. Jan.-Mar. pp. 361-414.

RODRIGUES, Virgilio (1938) - "Apontamentos para a história do ensino médio comercial". Revista de Contabilidade e Comércio, n." 21, JaneiroMarço. pp. 98-111.

SÁ, António Lopes de Sá (1993) - - "Uma hipótese sobre o aprendizado de Paciolo sobre as partidas dobradas". Revista de Contabilidade e Comércio, n." 199. pp. 335-345.

SÁ, António Lopes de Sá (1998) - História geral e das doutrinas da Contabilidade. 2." ed.. Lisboa : Vislis Editores.

SÁ, Ricardo José de (1919) - Tratado de Contabilidade. 2." ed. Lisboa : Livraria Editora.

SÁ, Ricardo José de (1926) - Escrituração comercial teórica e prálica para aprender sem Mestre. 2." ed.. Lisboa : Livraria Editora.

SANTANA, Francisco Gingeira (1985) " "A Aula do Comércio: uma escola burguesa em Lisboa". Ler História, n.. 4. pp. 19-30.

SARAIVA, José Hermano (1983) -- "Pombal e a experiência da autoridade". In SARAIVA, José Hermano (org) - História de Portugal. Vol. 5. Lisboa : Publicações Alfa. pp. 83-111.

SERRÃO, Joel (1981) - "Estrutura social, ideologias e sistemas de ensino". In SILVA, Manuela e TAMEN, M. Isabel (coord.) (1981) - Sistema de Ensino em Porlugal. Lisboa: Fundação Calouste Gulbenkian. pp. 17- 45.

SILVA, Fernando V. Gonçalves da (1938) - A regulamentação legal da escrituração mercantil: esboço crítico. Lisboa : Tipografia da Empresa Nacional de Publicidade.

SILVA, Fernando V. Gonçalves da (1948) - "Luca Pacioli: o Homem e a Obra“. Revista de Contabilidade e Comércio, n. ${ }^{\circ} 61 / 62$, ano XVI. pp. 5-27. 
SILVA, Fernando V. Gonçalves da (1948a) - "Curiosidades e Velharias: o livro de João Baptista Bonavie". Revista de Contabilidade e Comércio, n." 63 , Jul.-Set. pp. 226-227.

SILVA, Fernando V. Gonçalves da (1953) - "O ensino da Contabilidade nas Escolas Superiores de Economia". Revista de Contabilidade e Comércio, n. ${ }^{\circ} 81$, ano XXI. pp. 5-30.

SILVA, Fernando V. Gonçalves da (1970) - Curiosidades, velharias e miudezas contabilísticas. Lisboa : [s.n.].

SILVA, Fernando V. Gonçalves da (1984) - "Bosquejo duma sucinta História da Contabilidade em Portugal". Revista de Contabilidade e Comércio, n. 187/192, vol. XLVII/XLVIII, 1983-84. pp. 503-514.

SOUSA, José Fernandes de (1995) - "Luca Pacioli (1447-1517): alguns aspectos da vida e da obra no quinto centenário da publicação do 1. "tratado impresso de Contabilidade". In Luca Pacioli - Colectânea de artigos publicados na Revista de Contabilidade e Comércio (1995). Separata da Revista de Contabilidade c Comércio; Anexo ao Volume LII. pp. 87-104.

STEVELINCK, Ernest (1970) - La Compatbilité à travers les Âges. [s.l.]

- Bibliothéque Royale Albert $1{ }^{\mathrm{er}}$.

STEWART, R. E. (1992) - "Pluralizing our Past: Foucault in Accounting History". Accounting, Auditing and Accountability Joumal, vol. 5, n. ${ }^{\circ}$, pp. $57-73$.

TAVARES, Amândio Faustino Ferreira (1999) -- A Influência de Jaime Lopes Amorim no desenvolvimento da Contabilidade em Portugal. Braga : Universidade do Minho; Escola de Economia e Gestão. Tese de Mestrado em Contabilidade e Auditoria.

TORGAL, Luís (1982) - "Nota introdutória acerca do significado do Pombalismo" Revista de História das Ideias. O Marquês de Pombal e o seu tempo, Tomo I. Coimbra : Instituto de História e Teoria das Ideias. Faculdade de Letras. pp. 7-17.

TUA PEREDA (s/d) - "Pacioli, la Partida Doble y el Renacimiento". [Consult. 5 Abr. 2009].Disponível em

http://www.uady.mx/ contadur/revistas/ca bvp/06\%20historia $\% 20$ pacioli.pdf.

VIDAL, Caetano Léglise da Cruz (1983) - "O Ensino das Ciências Empresariais em Portugal". Revista de Contabilidade e Comércio, n. $185 / 6$, vol. XLVII. pp. $71-81$.

VLAEMMINCK, Joseph-H. (1961) - História e doctrinas de la Contabilidad. Tradução espanhola de José Maria Gonzalez Ferrando. Madrid : Editorial E.J.E.S. 